\title{
Uneven Recoveries from the Great Recession
}

\author{
Elizabeth M. Dolan ${ }^{1}$
}

Published online: 4 August 2016

(c) Springer Science+Business Media New York 2016

Although the Great Recession officially ended in June 2009, its deep effects are still being felt today. Employment levels have not rebounded in the US, nor in many other nations. Families have less income, less wealth, and more debt. Some families are suffering the consequences of unstable housing. Signs of recovery are emerging, however. In the United States, the national unemployment rate has dropped and world per capita real GDP is growing faster than expected. How have families faired during the Great Recession? The seven papers that make up the special section on recovering from the Great Recession provide insights into what happened to families and households, and, in some cases, how they coped with, and recovered from, the stresses experienced during the Great Recession.

When sources of income are lost, we expect to see savings decrease and debt increase. Rhine, Di, Greene, and Perlmeter addressed the question of what happens to savings accounts in "Savings account ownership during the Great Recession," using the US Survey of Consumer Finances (SCF). They found that families did maintain savings accounts during the economic downturn. Only when there was a substantial income loss did the incidence of owning a savings account decrease. Race/ethnicity was also a factor in maintaining savings during the Recession. Kim and Wilmarth, also using the SCF, took on the question of debt, specifically in lower income families in "Government subsidies and household debt burden after the Great Recession." They found that assistance (TANF, SNAP, SSI) may help low-income families' financial

Elizabeth M. Dolan

jfei.editor1@gmail.com; e.dolan@unh.edu

1 Dover, NH 03820, USA situation by lowering their reliance on debt, and/or by enabling them to reduce their debt load. For low-income families, government assistance may play an important role in helping them maintain a level of financial security.

Low income families tend to be the most vulnerable during an economic downturn as their employment options have the least amount of job security. Heflin, in "Instability and Maternal Hardship: Results from the 2008 Survey of Income and Program Participation," found that losing a job was indeed associated with a greater probability of low income mothers reporting medical, housing and/or expense hardships. Further, if a household had a person with a disability, there was an increased probability of medical, housing, and/or expense hardships, as well as an increase in the probability of food insecurity. The likelihood of food insecurity was reduced when income increased. Balistreri addressed the issue of food insecurity specifically in "A decade of change: Measuring the extent, depth and severity of food insecurity." Using the Current Population Survey Food Security Supplement, Balistreri discovered that the rate of food insecurity has remained constant despite an improving economy and that participation rates in SNAP almost doubled between 2008 and 2013. Food insecure households became more insecure during the Recession. The most rapid increase in insecurity was among households with children, and, while Black households maintained a more constant level of insecurity, White households experienced more food insecurity.

In the US, housing instability became common during the Great Recession for a variety of reasons. In "Looking back: The experiences of four Midwest families after receiving foreclosure counseling services," Tobe, Ames, and Carolan gained insight into the phenomenon of housing instability. They discovered, from this qualitative study, that the families were able to cope with their housing 
crisis through the help of counseling, and also several other key coping factors.

While not specifically focused on the Great Recession, the final two papers add more dimensions to our understanding of family stressors during difficult economic times. Lucero, Lim and Santiago addressed intimate partner violence (IPV) in "Changes in economic hardship and IPV: A family stress framework," using data from the Fragile Families and Child Well-Being Study. Those reporting the greatest increase in economic strain had the greatest odds of IPV. Further, those with the greatest economic strain also had the highest incidence of depressive symptoms. Lucero et al. concluded that economic strain reduces coping resources. And finally, Lebert and Voorpostel looked at job turnover in "Turnover as a strategy to escape job insecurity: The role of family determinants in dual-earner couples." Job insecurity is a characteristic of any recession. Using the Swiss Household Panel, Lebert and Voorpostel found that men with insecure jobs were more likely to voluntarily change jobs. This was also true for women unless they were mothers of preschool-aged children. Child-care responsibilities appeared to reduce employment flexibility for Swiss mothers.

The policy recommendations made by these authors are perhaps the most important part of the papers. Understanding what happens to families and households during severe recessions is important, but figuring out what might actually help those undergoing financial crises is ultimately the goal.

I would like to thank Dr. Peter Brandon of the University at Albany (NY) for helping with this special issue.

Elizabeth M. Dolan retired from the Department of Family Studies at the University of New Hampshire in 2013. Her primary research interest is the economy of the family, specifically low income, remarried, and same sex families. She is currently serving as the Editor in Chief of the Journal of Family and Economic Issues. She earned her Ph.D. from Virginia Tech. 